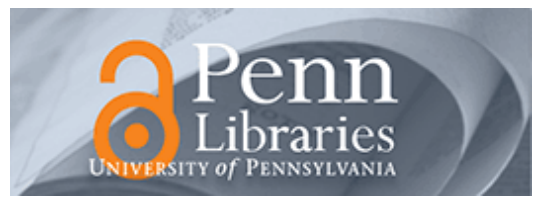

University of Pennsylvania

ScholarlyCommons

Marketing Papers

Wharton Faculty Research

8-1-1991

\title{
Strategic Planning Improves Manufacturing Performance
}

\author{
J. Scott Armstrong \\ University of Pennsylvania, armstrong@wharton.upenn.edu
}

Follow this and additional works at: https://repository.upenn.edu/marketing_papers

Part of the Marketing Commons

\section{Recommended Citation}

Armstrong, J. S. (1991). Strategic Planning Improves Manufacturing Performance. Retrieved from https://repository.upenn.edu/marketing_papers/121

Postprint version. Published in Long Range Planning, Volume 24, Issue 4, August 1991, pages 127-129.

Publisher URL: http://dx.doi.org/10.1016/0024-6301(91)90013-E

This paper is posted at ScholarlyCommons. https://repository.upenn.edu/marketing_papers/121

For more information, please contact repository@pobox.upenn.edu. 


\title{
Strategic Planning Improves Manufacturing Performance
}

\author{
Abstract \\ A quantitative critique of 28 studies concludes that formal planning is valuable for firms. The results were \\ particularly favorable for manufacturing firms: nine studies found formal planning to be associated with \\ better performance and none found detrimental performance. \\ Disciplines \\ Marketing \\ Comments \\ Postprint version. Published in Long Range Planning, Volume 24, Issue 4, August 1991, pages 127-129. \\ Publisher URL: http://dx.doi.org/10.1016/0024-6301(91)90013-E
}


Published in Long Range Planning, 24 (4), 1991,127-129.

\title{
Strategic Planning Improves Manufacturing Performance
}

\author{
J. Scott Armstrong \\ A quantitative critique of 28 studies concludes that formal planning is valuable for \\ firms. The results were particularly favorable for manufacturing firms: nine studies \\ found formal planning to be associated with better performance and none found \\ detrimental performance.
}

\begin{abstract}
Readers of Long Range Planning have had an enduring interest in the effects of formal planning systems on corporate performance [1,2]. According to Greenley's [3] review of the empirical evidence, formal planning has not been shown to be useful to manufacturing companies. My own review of the evidence reaches a more favorable verdict with respect to formal planning. Below, I describe the selection of the relevant evidence on formal vs. informal planning. Then I discuss how to interpret the previous studies on planning. Finally, I present additional evidence on the value of formal planning in manufacturing firms as well as in other organizations.
\end{abstract}

\section{Selection of the Evidence}

Greenley reached his conclusion by analyzing prior empirical research. He did not describe the procedure he used to search the literature. The literature he used was a subset of eight of the 19 studies examined in Armstrong [4] plus the rightful addition of Gershefski [5].

In deciding whether formal planning is useful to manufacturing companies, is it sensible to examine only studies conducted in manufacturing companies? Unless one has good prior knowledge that the management planning process is substantially different in manufacturing companies than it is in other types of organizations, it does not seem proper to restrict the search. Greenley presents no evidence on this issue. Because we do not know that the effectiveness of planning differs by type of firm, w( should incorporate evidence from all firms. This is especially important because Greenley had a small sample of studies relevant to manufacturing companies.

To consider the sampling problem in another way, assume that a manufacturer of light bulbs in New York wants to know whether formal planning will improve the firm's performance over the next 10 years. Would you respond, "I don't know because the sample in the study does not include any New York light bulb manufacturers during the years 1991 to 2000 ?" Researchers must generalize to new situations. They do this by marshalling relevant evidence from similar situations.

\section{Interpreting the Evidence}

Greenley concluded that five studies favored formal planning and that four did not. It is common practice in quantitative reviews (or, as they are now called, "meta-analyses") to omit studies scored as "ties" in the comparisons and to look only at the direction of effects. Of the four studies that did not support planning, three were coded as ties in Armstrong [6]; these were the study reported by Fulmer and Rue [7] and Rue and Fulmer [8] (Fulmer and Rue divided their study into two parts for publication; each part is similar), Grinyer and Norburn [9], and Lcontiadcs and Tezel [10]. The fourth study, Kudla [11, 12], was classified in Armstrong as favoring formal planning (Kudla split his study into two parts; it was necessary to read both parts in order to rate the study). My rating was based on independent assessments by three experts, with the resulting consensus being checked with the researcher, Kudla. Greenley did not state the basis for his rating of Kudla's study as a tie. (Although Shrader, Taylor, and Dalton [13] had also rated Kudla as a tie between formal and informal planning, they did not include 
the rest of his study, which was reported separately.) By coding Kudla as a positive case for the value of planning, Greenley's sample contains six comparisons favoring formal planning and none opposed. A six to nothing advantage is statistically significant ( $\mathrm{p}<0.05$ using the sign test).

In Greenley's favor, one should note that the three studies with no effects should not be completely ignored. They weaken the case for the value of formal planning. That is, if we do many studies and find no effect, then the likelihood rises that there will be no effect in a new situation.

Greenley also concluded that the researchers were biased in favor of formal planning and that this should lead us to be less accepting of positive results. To examine this, he used a measure of methodological rigor corresponding to the approach presented in Armstrong [14]. This scale for rigor was taken from Terpstra [15]. Coincident with the publication of Greenley's paper, two papers appeared on the use of this test of methodological rigor: Foster [16] challenged the use of Terpstra's scale, while Armstrong [17] defended it. Although the measure is not without its problems, it does seem to be useful.

I disagree with Greenley's interpretation of the results from the test of methodological rigor. Presumably, studies done with little rigor are likely to yield results that reflect the researcher's bias. If researchers are biased in favor of formal planning, one would expect stronger results to be found among less rigorous studies. Armstrong [18] found the opposite to be true; the studies that were done more carefully provided stronger evidence in favor of formal planning. Greenley's results were consistent with Armstrong, but Greenley interpreted this as weakening the argument in favor of formal planning.

\section{Additional Evidence}

Research on the value of formal planning continues. The meta-analysis from Armstrong [19] should be updated to include nine studies favoring formal planning: Gershefski [5], Robinson et al. [20], Welch [21], Ackelsberg and Arlow [22], Bracket and Pearson [23], Ramanujam and Venkatraman [24], Rhyne [25], Capon et al. [26], and Verhage and Waarts [27], one with no effect Van der Walt et al. [28], and one, Whitehead and Gupta [29], with negative effects. The updated evidence on the value of formal planning vs. informal is as follows:

20 studies found higher performance with formal planning

5 studies found no difference

3 found formal planning to be detrimental.

Thus, formal planning, as practiced, does seem useful and the results are statistically significant $(p<0.001$ using the sign test).

Of these new studies, three $[21,25,26]$ were based on manufacturing firms. In these studies, formal planning was associated with better performance. Thus the updated score for manufacturing firms is that all nine studies with differences found formal planning to be associated with improved financial performance.

Despite these positive results on the value of planning, some of the procedures labeled as formal planning are misused [30]. For example, formal planning is sometimes used in an authoritarian manner that can produce resentment in an organization. To find evidence on which planning practices are most likely to help, one can draw upon laboratory experiments in organizational behavior.

\section{Further Research}

I agree with Greenley's call for more research. One central point of his paper is correct: It is important to define better the conditions under which formal planning is useful. We should also study what planning techniques are useful and how the techniques should be matched to the situation, because many concerns persist regarding the shortcomings of planning practice. 
This research could best be done using laboratory research or quasi-experimental research in organizations. As demonstrated by Van de Ven [31], experimental research of the planning process in organizations is feasible.

\section{Conclusions}

Greenley [3] concluded that formal planning was not useful for manufacturing firms. A re-analysis of the evidence on the value of formal planning shows that, in fact, planning is useful for manufacturing companies. Of the 12 studies on manufacturing firms, nine found that formal planning was more successful, and in no study was it detrimental. These results arc stronger than those for 16 studies that included other types of firms. In those studies, formal planning was superior on 11 and detrimental on three, with two ties.

Acknowledgement: The author wishes to thank Gordon Greenley for his helpful suggestions.

\section{References}

[1] J. C. Camillus (1975), "Evaluating the benefits of formal planning systems," Long Range Planning, June.

[2] D. M. Reid (1990), “Where planning fails in practice,” Long Range Planning, 23 (5), 85-93.

[3] G. E. Greenley (1986), "Does strategic planning improve company performance?" Long Range Planning, 19 (2), 101-109.

[4] J. S. Armstrong (1982), "The value of formal planning for strategic decisions: Review of empirical research," Strategic Management Journal, 3 (3), 197-211.

[5] G. W. Gershefski (1970), "Corporate models - The state of the art," Management Science, 16 (6), B303-B312.

[6] See Ref. 4.

[7] R. M. Fulmer and L. W. Rue (1974), “The practice and profitability of long-range planning," Managerial Planning, 22, 1-7.

[8] L. W. Rue and R. M. Fulmer (1973), "Is long-range planning profitable?" Proceedings of the Academy of Management, Boston, MA, pp. 66-73.

[9] P. H. Grmyer and D. Norburn (1975), "Planning for existing markets: Perceptions of executives and financial performance," Journal of the Royal Statistical Society (A), 138 (1), 70-97.

[10] M. Leontiades and A. Tezel (1980), "Planning perceptions and planning results," Strategic Management Journal, 1 (1), 65-75.

[11] R. J. Kudla (1980), “The effects of planning on common stock returns," Academy of Management Journal, 23 (1), 5-20.

[12] R. J. Kudla (1981), "Strategic planning and risk," Review of Business and Economic Research, 17 (1), 2-14.

[13] C. B. Shrader, L. Taylor and D. R. Dalton (1984), "Strategic planning and organizational performance: A critical appraisal," Journal of Management, 10 (2), 149-171.

[14] See Ref. 4. 
[15] D. Terpstra (1981), "Relationship between methodological rigor and reported outcomes in organizational development evaluation research," Journal of Applied Psychology, 66 (5), 541-543.

[16] M. J. Foster (1986), “The value of formal planning for strategic decisions: A comment," Strategic Management Journal, 7 (2), 179-182.

[17] J. S. Armstrong (1986), "The value of formal planning for strategic decisions: Reply," Strategic Management Journal, 7 (2), 183-185; and J. S. Armstrong (1990), "Review of Corporate Strategic Planning by Capon et al.," Journal of Marketing, 54, 114-119, April.

[18] See Ref. 4.

[19] See Ref. 17.

[20] Richard B. Robinson Jr., J. A. Pearce, G. S. Vozikis and T. S. Mescon (1984), “The relationship between stage of development and small firm planning and performance," Journal of Small Business Development, 22 (2), $45-52$.

[21] Jonathan B. Welch (1984), "Strategic planning could improve your share price," Long Range Planning, 17, 144-147.

[22]Robert Ackelsberg and P. Arlow (1985), "Small businesses do plan and it pays off," Long Range Planning, 18 (5), 61-67.

[23] Jeffrey S. Bracker and J. N. Pearson (1986), "Planning and performance of small, mature firms," Strategic Management Journal, 7, 503-522.

[24] Vasudevan Ramanujam and N. Venkatraman (1987), "Planning and performance: A new look at an old question," Business Horizons, 30, 19-25.7

[25] Lawrence Rhyne (1987), "Contrasting planning systems in high, medium and low performance companies," Journal of Management Studies, 24, 363-385.

[26] N. Capon, J. U. Farley and J. M. Hulbert (1987), Corporate Strategic Planning: An Empirical Study. New York: Columbia University Press.

[27] Bronislaw J. Verhage and E. Waarts (1988), "Marketing planning for improved performance: A comparative analysis," International Marketing Review, 5 (2), 20-30.

[28] Nick T. Van der Walt, S. Lysonski, B. Queree, J. Harper and S. Hales (1989), "Marketing planning in New Zealand (with commentary)," New Zealand Journal of Business, 11, 1-21.

[29] David D. Whitehead and B. E. Gun (1985), "Bank and thrift profitability Does strategic planning really pay?" Economic Review of the Federal Reserve Bank of Atlanta, 70 (9), 14-25.

[30] Marjorie A. Lyles and R. T. Lenz (1982), "Managing the planning process: A field study of the human side of planning," Strategic Management Journal, 3, 105-118.

[31] A. Van de Ven (1980), "Problem solving, planning and innovation, Part $1:$ Test of the program planning model," Human Relations, 33 (10), 711-740. 